\title{
A panel of antibodies for the immunostaining of Bouin's fixed bone marrow trephine biopsies
}

Jean-Luc Gala, Frédérique Chenut, Khang Bui Thi Hong, Jean Rodhain, Philippe Camby, Marianne Philippe, Jean-Marie Scheiff

\begin{abstract}
Aims-To assess a panel of antibodies on Bouin's fixed bone marrow trephine (BMT) biopsies. These biopsies are widely used in routine diagnosis of various haematological malignancies and may be the sole material available in many centres; however, information regarding the immunostaining of this material is lacking.

Methods-Biopsies were taken from 72 patients presenting with various haematological malignancies (leukaemia, 38; lymphoma, 14; multiple myeloma, 20). A panel of antibodies was assessed on Bouin's fixed BMT biopsies by the alkaline phosphatase-antialkaline phosphatase method.

Results-Three B (MB2, LN-2, Ki-B5) and two $T$ cell lineage antibodies (UCHL-1, CD3-r) reliably identified lymphoid cells, while MPO-r, Leu-M1/CD15, and KP-1/CD68 recognised cells from the myeloid or histiocytic/macrophage series. Reed-Sternberg cells were stained by LN-2, Leu-M1, and CD30. Antibodies specific for plasma cells (VS38) and hairy cells (DBA.44) gave a variable pattern of staining. Among the proliferation markers, proliferative cell nuclear antigen but not Ki-67 related antibodies were effective.

Conclusion-This study presents a panel of antibodies with reactivity not restricted to common fixatives that are also suitable for Bouin's fixed BMT biopsies.

(F Clin Pathol 1997;50:521-524)
\end{abstract}

Keywords: Bouin's fixative; bone marrow trephine biopsy; immunostaining

Immunohistochemical evaluation in bone marrow trephine (BMT) biopsies appears to be a useful adjunct to the diagnosis and pathological staging of haematological neoplasms, and contributes to a better identification of the invading malignant cells. ${ }^{1-3}$ The majority of monoclonal or polyclonal antibodies (MoAb, $\mathrm{PoAb}$ ) is useful on unfixed and undecalcified snap frozen material cut in a cryostat, however, such material is not readily available. Fresh or frozen tissues, which are not suitable for long term preservation, require complex processing and storage. A large panel of MoAb and PoAb recognising epitopes that survive histological processing is available, ${ }^{4}$ and this allows immunodetection of a wide variety of cells in

\section{Table 1 Haematological neoplasms}

\begin{tabular}{ll}
\hline Neoplasm & Number of samples \\
\hline Leukaemia & 38 \\
Acute lymphoblastic B type & 4 \\
Acute lymphoblastic T type & 2 \\
Chronic lymphocytic B type & 19 \\
Chronic lymphocytic T type & 1 \\
Hairy cell & 3 \\
Acute myeloid & 9 \\
Lymphomas & 14 \\
Follicular with $\mathrm{t}(14 ; 18)$ & 2 \\
Mantle zone with $\mathrm{t}(11 ; 14)$ & 3 \\
Burkitt's & 5 \\
Hodkin's & 4 \\
Multiple myeloma & 20
\end{tabular}

Diagnoses were based on typical features found by cytology or histology, cytogenetics, immunophenotype, biochemistry, and molecular biology using conventional methods.

routinely fixed, decalcified, paraffin wax embedded bone marrow biopsies. ${ }^{1-6}$ Activity of these antibodies is usually assessed on buffered formalin, B5 or Zenker fixed tissues. ${ }^{3-5}$ Very few data report the reactivity of the antibodies on Bouin's fixed BMT biopsies. Lack of immunostaining has been reported on these biopsies $^{12}$ that, at least partially, explains why this fixative is not the first choice for immunostaining of this material. Nevertheless, Bouin's fixed BMT biopsies are widely used in routine diagnosis of various haematological malignancies, and is the sole material available in many centres.

We report experience of immunostaining Bouin's fixed BMT biopsies using a panel of the newest $\mathrm{MoAb}$ and PoAb. ${ }^{48}$ Labelling was assessed on common haematological neoplasms.

\section{Material and methods}

Seventy two samples were obtained from patients presenting with various haematological neoplasms (table 1): leukaemia $(n=38)$, lymphoma $(\mathrm{n}=14)$, and multiple myeloma $(n=20)$. Bouin's fixed BMT biopsies from patients with non-malignant haematological disorders $(n=8)$ were also included. All diagnoses were based on typical features found by cytology or histology, cytogenetics, immunophenotype, biochemistry, and molecular biology using conventional methods.

Bone marrow biopsies were all placed in Bouin's fixative (copper acetate monohydrate $25 \mathrm{~g}$, picric acid $40 \mathrm{~g}$, distilled water $1000 \mathrm{ml}$, formalin $100 \mathrm{ml}$, acetic acid $15 \mathrm{ml}$ ) for no longer than 24 hours, decalcified for six hours in $7.5 \%$ nitric acid, and embedded in paraffin. Before immunostaining, each Bouin's fixed BMT biopsy was dewaxed and rehydrated. The 
Table 2 Antibodies assessed on Bouin's fixed bone marrow trephine biopsies

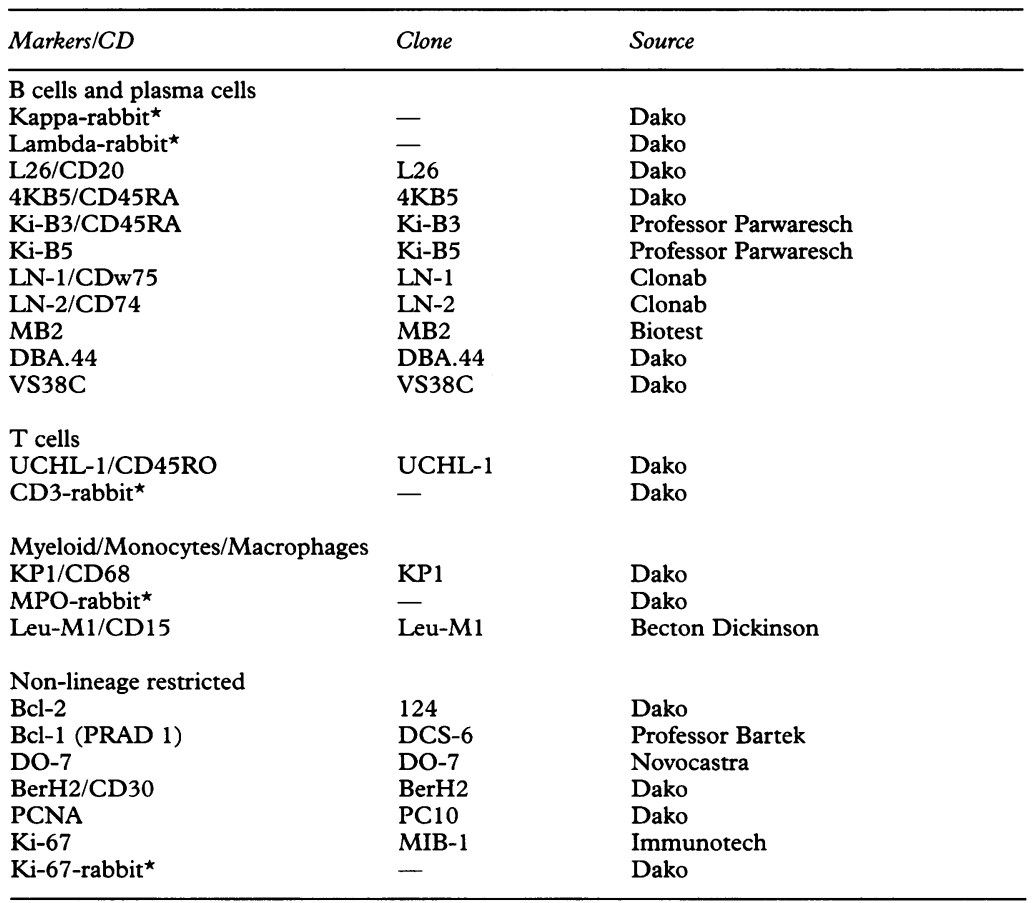

Dako, Dakopatts, Prosan, Belgium; Biotest, Biotest Diagnostics, Dreieich, Germany. Professor Bartek is at the Danish Cancer Society, Copenhagen, Denmark and Professor Parwaresch is at the Institut für Hämatopathologie, Kiel, Germany.

*Polyclonal antibody.

Table 3 Results of Bouin's fixed bone marrow trephine immunostaining

\begin{tabular}{|c|c|c|c|}
\hline Markers/CD & $\begin{array}{l}\text { Working antibodies } \\
\text { (retrieval } \\
\text { procedure) }\end{array}$ & Dilution & Malignancies \\
\hline \multicolumn{4}{|c|}{ B cells and plasma cells } \\
\hline Kappa-rabbit & + & $1 / 10000$ & MM \\
\hline Lambda-rabbit & + & $1 / 10000$ & MM \\
\hline $\mathrm{L} 26 / \mathrm{CD} 20$ & $-(M W)$ & & B-LLC, HC, FL, MZ \\
\hline 4KB5/CD45RA & $+/-(M W)$ & $1 / 25$ & B-LLC, HC, FL, MZ, Co \\
\hline Ki-B3/CD45RA & $+/-(\mathrm{MW})$ & & B-LLC, HC, FL, MZ, Co \\
\hline Ki-B5 & + & $1 / 1$ & B-LLC, HC, FL, MZ, Co \\
\hline LN-1/CDw75 & - & & $\mathrm{HC}, \mathrm{HD}$ \\
\hline LN-2/CD74 & + & $1 / 50$ & B-LLC, HC, HD, FL, MZ, Co \\
\hline MB2 & + & $1 / 50$ & B-LLC, HC, FL, MZ, Co \\
\hline DBA.44 & t/- (MW/Enz) & $1 / 50$ & $\mathrm{HC}$ \\
\hline VS38C & $+/-(\mathrm{MW})$ & $1 / 50$ & MM \\
\hline \multicolumn{4}{|l|}{$\mathrm{T}$ cells } \\
\hline UCHL-1/CD45RO & + & $1 / 50$ & T-CLL, T-ALL, Co \\
\hline CD3-rabbit & + & $1 / 100$ & T-CLL, T-ALL, Co \\
\hline \multicolumn{4}{|c|}{ Myeloid/Monocytes/Macrophages } \\
\hline $\mathrm{KP} 1 / \mathrm{CD} 68$ & + & $1 / 50$ & AML, MM \\
\hline MPO-rabbit & + & $1 / 100$ & AML \\
\hline Leu-M1 / CD15 & + & $1 / 50$ & AML, HD \\
\hline \multicolumn{4}{|l|}{ Non-lineage restricted } \\
\hline Bcl-2 & + & $1 / 80$ & B-ALL, B-CLL, FL, MM \\
\hline Bcl-1 (PRAD 1) & $-(M W)$ & & $\mathrm{MZ}$ \\
\hline DO-7 & $-(M W)$ & & B-CLL* \\
\hline BerH2/CD30 & + & $1 / 50$ & HD \\
\hline PCNA & + & $1 / 100$ & $\mathrm{BL}$ \\
\hline Ki-67 & $-(\mathrm{MW})$ & & BL \\
\hline Ki-67-Rabbit & $-(\mathrm{MW})$ & & BL \\
\hline
\end{tabular}

B-ALL/T-ALL, B cell type/T cell type acute lymphoblastic leukaemia; B-CLL/T-CLL, B cell type/T cell type chronic lymphocytic leukaemia; BL, Burkitt's lymphoma; $\mathrm{Co}$, non-malignant Bouin's fixed BMT biopsy; FL, follicular (centrocytic-centroblastic) lymphoma; HD, Hodgkin's disease; MM, multiple myeloma; MZ, mantle zone lymphoma; $M W$, antigen retrieval by microwave heating; Enz, antigen retrieval by enzymatic digestion.

${ }^{\star} B$ cell CLL patient disclosing a p53 missense mutation.

alkaline phosphatase-antialkaline phosphatase staining, used to avoid the problem of endogenous peroxidase, was performed as described previously. ${ }^{6}$

Antibodies tested and optimal dilutions are listed in table 2. They were incubated for one hour, except for CD3-r ( $\mathrm{r}=$ rabbit), $\mathrm{Ki}-67-\mathrm{r}$, lambda, and kappa that were incubated overnight. Isotype matched monoclonal antibodies were included as a control for nonspecific binding. Slides were examined under a light microscope and evaluated for staining intensity, graded from 0 to $5+$. Each antibody unreactive after conventional procedure was reassessed after microwave heating (five cycles of three minutes each in citrate buffer $\mathrm{pH}$ 5.7) or enzymatic digestion with pronase, according to the manufacturer's instructions and literature. ${ }^{9}$

\section{Results}

The results are summarised in table 3 .

\section{B CELL AND PLASMA CELLS ASSOCIATED} ANTIBODIES

Kappa and lambda-Both polyclonal antibodies positively stained $(3+$ or $4+)$ plasma cells in multiple myelomas, allowing the detection of monotypy.

$L 26,4 K B 5, K i-B 3, L N-1$ - We confirmed a lack of staining with L26 ${ }^{12}$ on B cell malignancies (chronic lymphocytic, hairy cell) regardless of microwave heating procedure. Unlike previous data, ${ }^{36}$ neither Reed-Sternberg nor hairy cell leukaemia biopsies reacted with $\mathrm{LN}-1$, and $\mathrm{B}$ cell malignancies were either inconsistently positive or very weakly stained $(0$ or $1+)$ with $4 \mathrm{~KB} 5$ and $\mathrm{Ki}-\mathrm{B} 3$.

$L N-2, M B 2, K i-B 5-\mathrm{LN}-2, \mathrm{MB} 2$, and the more recently described $\mathrm{MoAb} \mathrm{Ki}-\mathrm{B} 5^{7}$ strongly labelled all chronic lymphocytic $B$ cell and hairy cell leukaemia biopsies (fig 1A), as well as follicular lymphomas, mantle zone lymphomas, and normal B lymphocytes ( $3+$ to $5+$ ). To the best of our knowledge, the reactivity of Ki-B5 recognising normal and neoplastic B cells has not been previously reported in BMT biopsies. LN-2 also identified Reed-Sternberg and Hodgkin's cells in all Hodgkin's disease biopsies assessed ( $3+$ or $4+)$. MB2 reacted as expected with endothelial cells but stained only $50 \%$ of multiple myelomas.

$D B A .44$ - Proposed as a hairy cell marker, ${ }^{4}$ this $\mathrm{MoAb}$ labelled only one of the three hairy cell biopsies $(2+)$. Noteworthy, staining was markedly intensified (4+) by pronase and by microwave heating, but only in the single positive case.

VS38-The use of microwave heating was mandatory with this recently discovered plasma cell marker. ${ }^{8}$ Variable immunostaining of normal and malignant plasma was observed (0 to $4+$ ). On most slides, strongly positive malignant plasma cells, observed on the border of heavily infiltrated slides (fig 1B), coexisted with totally negative cells in the centre of the biopsy, demonstrating the variability of labelling due to the quality of the fixation (poorer in the middle of the tissue).

\section{T CELL ASSOCIATED ANTIBODIES}

$U C H L-1, C D 3-r$-Both $\mathrm{T}$ lineage antibodies, which are recommended for the diagnosis of $T$ cell lymphomas in paraffin wax embedded sections, ${ }^{10}$ stained clearly normal and malig- 
nant $\mathrm{T}$ cells. Staining with UCHL-1 was usually stronger (4+ to $5+$ ) than with CD3-r $(2+$ to $3+)$. In concert with others, we found staining of myeloid cells with UCHL $-1 .^{6}$

MYELOID/MONOCYTE/MACROPHAGE ASSOCIATED ANTIBODIES

KP1/CD68, MPO, Leu-M1/CD15-KP1 reacted with marrow monocytes and macrophages in normal and pathological Bouin's fixed BMT biopsies (4+ or $5+$ ) (fig 1C), and strongly labelled myeloid cells in eight of nine acute myeloid leukaemias. Rabbit PoAb (MPO) against myeloperoxidase labelled blast cells in nine of nine myeloid malignancies (4+ or $5+$ ) (fig 1D). Leu-M1 stained mature granulocytic cells and monocytes $(5+)$, three of seven acute myeloid leukaemias $(4+$ or $5+$ ), and Reed-Sternberg cells in four of four Hodgkin's disease biopsies ( $3+$ or $4+$ ) (fig 1E).

NON-LINEAGE ASSOCIATED ANTIBODIES

$\mathrm{Bcl}-2, \mathrm{Bcl}-1, \mathrm{DO}-7$-Among the antibodies to oncoproteins, bcl-2 but not DO-7 or bcl-1 (PRAD D1/cyclin D1) reacted on Bouin's fixed BMT biopsies. Anti-bcl-2 MoAb consistently stained follicular lymphoma (5+) (fig $1 F)$, chronic lymphocytic B cell leukaemia (3+ to $5+$ ), acute lymphoblastic leukaemia $(4+$ or $5+)$, and multiple myeloma (2+ to $5+)$, but, as expected, none of the Burkitt's lymphomas."

CD30-Like LN-2, CD30 labelled the ReedSternberg cells in four of four Hodgkin's disease biopsies.

PCNA, MiB-1, Ki-67-r-Despite microwave heating, no staining was observed with either
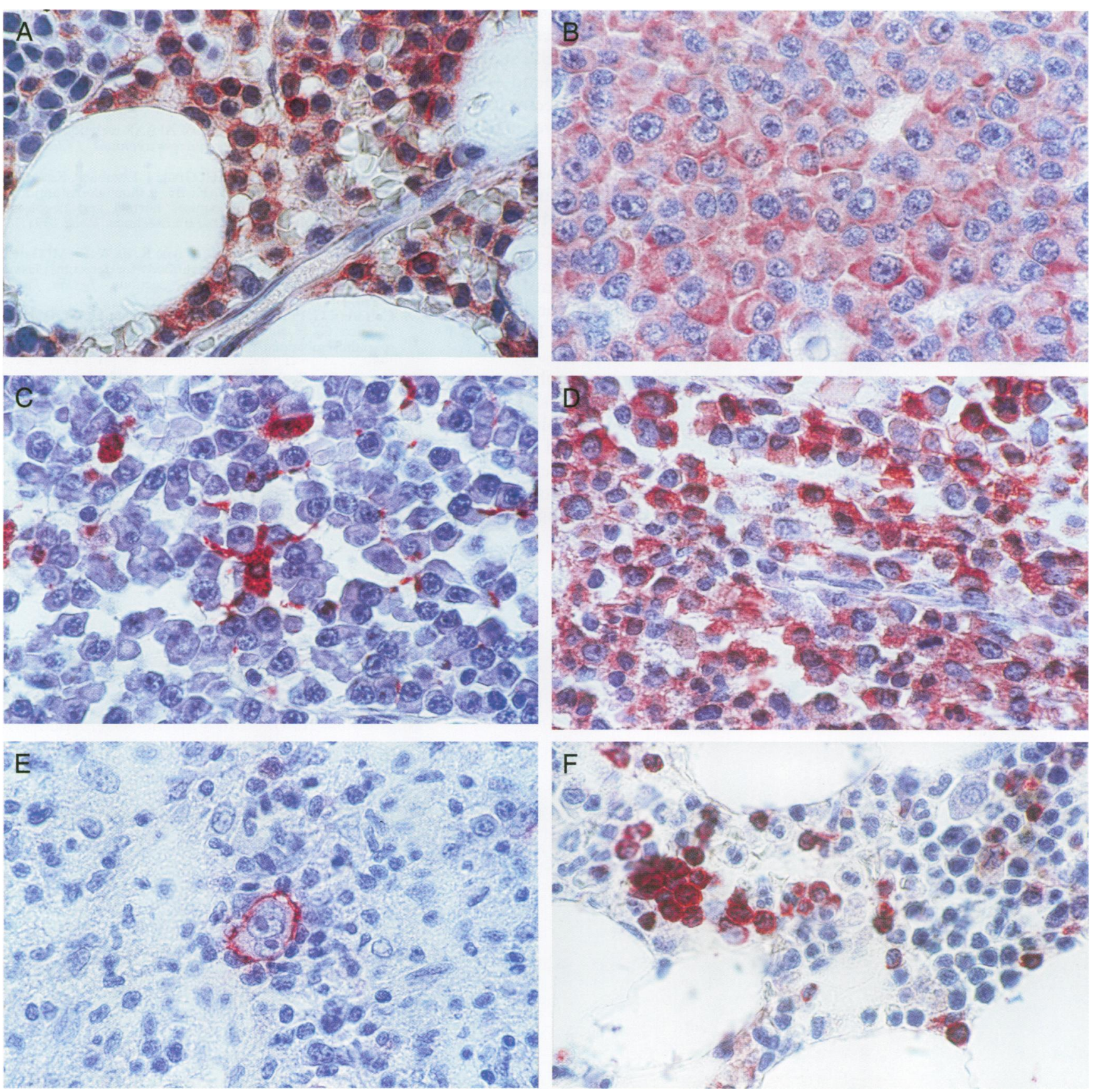

Figure 1 (A) Group of hairy cells reacting with Ki-B5; (B) VS38 positive multiple myeloma cells; (C) Cellular contact between KP1 positive macrophage and plasma cells; (D) Staining of myeloblasts by MPO in a case of acute myeloid leukaemia; (E) Typical Reed-Sternberg cell reacting with Leu-M1; $(F)$ bcl-2 labelling of infiltrating follicular lymphoma cells. 
MoAb or PoAb recognising the $\mathrm{Ki}-67$ antigen. On the contrary, nuclear localisation of proliferative cell nuclear antigen (PCNA) was demonstrated in more than $80 \%$ of the malignant cells in highly proliferative Burkitt's lymphoma $(4+$ or $5+)$ without antigen retrieval.

\section{Discussion}

Among the antibodies tested, several demonstrated excellent immunoreactivity on tissues from Bouin's fixed BMT biopsies. The antigenic specificity on pathological marrows was in accordance with previously reported data. ${ }^{469}$ However, the weak and inconsistent immunolabelling with some MoAb that recognise formalin resistant antigen (4KB5, Ki-B3) renders them inappropriate for immunostaining of Bouin's fixed BMT biopsies. Lack of staining was observed with DBA.44 from two florid hairy cell leukaemia biopsies, whereas they were strongly positive with MB2, suggesting that DBA.44 labelling may depend on the exposure to Bouin's fixative. This seems also to apply to VS38 where strong positive or totally negative labelling of normal and malignant plasma cells was striking on the same slides. Interestingly, this staining variability was not observed with other antibodies (MB2, LN-2, Ki-B5, UCHL-1, CD3-r, PCNA, CD30, LeuM1). Noteworthy, preliminary microwave heating, recommended by the manufacturer's instruction, was not mandatory for immunostaining of Bouin's fixed BMT with Pab CD3-r or CD30.

In conclusion, reliable immunophenotyping of archival Bouin's fixed BMT biopsies is feasible. While demonstrating the variable degree of reactivity obtained on Bouin's fixed and decalcified tissues with some widely used or more recent antibodies, this study presents a panel of antibodies suitable for phenotyping the most common haematological neoplasms on this material.

This study was fully supported by the association Salus Sanguinis. We thank Professor Bartek, Danish Cancer Society, Copenhagen, Denmark and Professor Parwaresch, Institut für Hämatopathologie, Kiel, Germany for the generous gift of anti body, Dr M Zandecki, Hôpital Calmette, Lille, France for critical reading of the manuscript and useful discussions, and Prosan, Dako, Belgium for its contribution.

1 Ellison DJ, Sharpe RW, Robbins BA, Spinosa JC, Leopard JD, Saven A, et al. Immunomorphologic analysis of bone marrow biopsies after treatment with 2-chlorodeoxyadenosine for hairy cell leukemia. Blood 1994;84:4310-15

2 Hakimian D, Tallman MS, Kiley C, Peterson LO. Detection of minimal residual disease by immunostaining of bone marrow biopsies after 2-chlorodeoxyadenosine for hairy cell leukemia. Blood 1993;6:1798-802.

3 Kubic VL, Brunning RD. Immunohistochemical evaluation Kubic VL, Brunning RD. Immunohistochemical evaluation
of neoplasms in bone marrow biopsies using monoclonal of neoplasms in bone marrow biopsies using monoclonal antibodies reactive in paraf
Pathology 1989;2:61 8-29.

4 Perkins SL, Kjeldsberg CR. Immunophenotyping of lymphomas and leukemias in paraffin-embedded tissues. $A m \mathcal{F}$ Clin Pathol 1993;99:362-73.

5 Horny HP, Wehrmann $M$, Griesser $H$, Tiemann $M$, Bültmann B, Kaiserling $E$. Investigation of bone marrow ymphocyte subsets in normal, reactive, and neoplastic lymphocyte subsets in normal, reactive, and neoplastic Clin Pathol 1993;99:142-9.

6 Erber WE, McLachlan J. Use of APAAP technique on paraffin wax embedded bone marrow trephines. $\mathcal{f}$ Clin Pathol 1989;42:1201-5.

7 Hansmann ML, Wacker HH, Gralla J, Lumbeck, Kossmahl $\mathrm{M}$, Heidebrecht $\mathrm{HJ}$, et al. Ki-B5: a monoclonal antibody unrelated to CD45 recognizes normal and neoplastic human B cells in routine paraffin sections. Blood 1991;77: 809-17.

8 Turley H, Jones M, Erber W, Mayne K, de Waele M, Gatter K. VS38: a new monoclonal antibody for detecting plasma cell differentiation in routine sections. $\mathcal{f}$ Clin Pathol 1994;47:418-22.

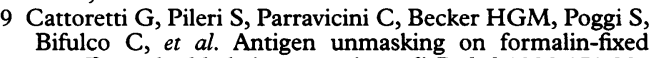
paraffin-embedded tissue sections. F Pathol 1993;171:8398

10 Kurtin PJ, Roche PC. Immunoperoxidase staining of non-Hodgkin's lymphomas for T-cell lineage associated antigens in paraffin sections. Comparison of the performance characteristics of four commercially available antibody preparations. Am ₹ Surg Pathol 1993;17:898-904.

11 Gala JL, Vermylen C, Cornu G, Ferrant A, Michaux JL, Philippe $M$, et al. High expression of bcl-2 is the rule in acute lymphoblastic leukemia except in Burkitt subtype at presentation, and is not correlated with the prognosis. Ann presentation, and is not 